\title{
Fatores de risco para mortalidade em pacientes com doença falciforme: uma revisão integrativa
}

\author{
Risk factors for mortality in patients with sickle cell disease: an integrative review
}

Factores de riesgo para la mortalidad en pacientes con enfermedad falciforme: una revisión integradora

\author{
Carolina Mariano Pompeo ${ }^{1}$ (c) \\ Andreia Insabralde de Queiroz Cardoso ${ }^{1}$ (D) \\ Mercy da Costa Souza ${ }^{1}$ (B) \\ Mayara Bontempo Ferraz ${ }^{1}$ (D) \\ Marcos Antonio Ferreira Júnior ${ }^{1,2}$ (i) \\ Maria Lúcia Ivo ${ }^{1}$ (D)
}

1. Universidade Federal de Mato Grosso do

Sul. Campo Grande, MS, Brasil.

2. Universidade Federal do Rio Grande do

Norte. Natal, RN, Brasil.

\section{RESUMO}

Objetivo: Sumarizar fatores de risco e indicadores de mortalidade em pacientes com doença falciforme. Método: Revisão integrativa em periódicos indexados nas bases de dados CINAHL, PubMed/MEDLINE, Science Direct/SCOPUS, SciELO e Web of Science. A questão norteadora foi elaborada por meio da estratégia Population, variable, outcome (PVO). A busca ocorreu no portal de periódicos da Coordenação de Aperfeiçoamento de Pessoal de Nível Superior entre outubro e novembro de 2018. Resultados: Dos 19 artigos, 18 eram coorte e um ensaio clínico randomizado. A amostra foi constituída, em sua maioria, pelo sexo feminino e genótipo HbSS. Se repetiram mais a taxa de mortalidade cumulativa e a curva de mortalidade global. Sete estudos identificaram fatores de risco com associação estatisticamente significativa para morte. Os mais frequentes foram o baixo nível de hemoglobina, variáveis hepáticas (enzimas fosfatase alcalina e transaminase glutâmico oxalacética) e cardiovasculares (velocidade de regurgitação da válvula tricúspide $\geq 2,5 \mathrm{~m} / \mathrm{s}$ ). Conclusão e implicações para a prática: Indicadores de mortalidade constituem ferramentas de manejo de pacientes com doença falciforme e prevenção de riscos e complicações. Há necessidade de estudos sobre os fatores relacionados à mortalidade desses pacientes. A prevenção do óbito, certamente, promoverá uma melhoria na qualidade de vida e na sobrevida dessa população.

Palavras-chave: Doença falciforme; Causas de morte; Taxas, razões e proporções.

\section{ABSTRACT}

Objective: To summarize the risk factors and mortality indicators in sickle cell disease patients. Method: Integrative review searched publications in journals in CINAHL, PubMed/MEDLINE, Science Direct/SCOPUS, SciELO, and Web of Science databases. The guiding question was elaborated through the Population, variable, outcome (PVO) strategy and the search was from October-to-November 2018, at the Coordination of Higher Level Personnel Improvement Periodicals' Gate. The keywords anemia, sickle cell "and" mortality "and" survival and their synonyms were used. Results: From 18/19 articles were cohort and one randomized controlled trial. The sample consisted mostly of females and HbSS genotype. The cumulative mortality rate and the overall mortality curve were the most repeated. Seven studies identified risk factors with a statistically significant association with death. The most frequent were low hemoglobin level, liver variables (alkaline phosphatase and oxalacetic glutamic transaminase enzymes) and cardiovascular variables (tricuspid valve regurgitation speed $\geq 2.5 \mathrm{~m} / \mathrm{s}$ ). Conclusion and implications for practice: Mortality indicators are tools for better management of sickle cell disease's patient, prevention of risks and complications. There is a need for further studies on the factors related to mortality of these patients. Preventing the causes that lead to death will certainly improve the quality of life and survival of this population.

Keywords: Sickle Cell Disease; Causes of death; Rates, rations and proportions.

\section{RESUMEN}

Objetivo: Resumir los factores de riesgo y los indicadores de mortalidad en pacientes con enfermedad de células falciformes. Método: revisión integradora de publicaciones en las bases de datos CINAHL, PubMed/MEDLINE, Science Direct/SCOPUS, SciELO y Web of Science. La pregunta guía basada en Population, variable, outcome (PVO) conduciu la búsqueda en el Portal de revistas de la Coordinación de Mejoramiento de Personal de Nivel Superior, entre octubre-noviembre de 2018, con los descriptores anemia, sickle cell "and" mortality "and" survival y sus sinónimos. Resultados: De 18/19 artículos son cohortes y un ensayo controlado aleatorio. La muestra consistió en mujeres y genotipo HbSS. La tasa de mortalidad acumulada y la curva de mortalidad general fueron más repetidas. Siete estudios identificaron factores de riesgo con asociación estadísticamente significativa con la muerte. Los más frecuentes fueron el bajo nivel de hemoglobina, variables hepáticas (fosfatasa alcalina y enzimas glutámicas transaminasas oxalacéticas) y variables cardiovasculares (velocidad de regurgitación de la válvula tricúspide $\geq 2.5 \mathrm{~m} / \mathrm{s}$ ). Conclusión e implicaciones para la práctica: Los indicadores de mortalidad son herramientas de manejo de los pacientes con esta enfermedad, la prevención de factores de riesgo y complicaciones. Hace necesidad de estudios sobre los factores relacionados con la mortalidad. La prevención de las muertes mejorará la calidad de vida y la supervivencia.

Palabras clave: Enfermedad falciforme; Causas de muerte; Tasas, razones y proporciones. 


\section{INTRODUÇÃO}

Doença Falciforme (DF) é um termo amplo, utilizado para agrupar diversas condições hematológicas de caráter hereditário que decorrem de uma única mutação genética que pode levar à formação de eritrócitos anormais. É uma doença multissistêmica, cujas células anormais na presença de desoxigenação podem sofrer danos em sua forma e em sua capacidade carrear gases sanguíneos, além de gerar diversos quadros de vaso oclusão que podem culminar em inúmeras alterações em órgãos do corpo. ${ }^{1}$

A herança de alelos falciformes determina as formas de DF, sendo a mais comum e mais grave a homozigótica HbSS, denominada anemia falciforme. Entre as outras formas, estão as heterozigóticas $\mathrm{HbSC}, \mathrm{HbS} \beta$-talassemias, HbSD e HbSOArab, que são hemoglobinopatias compostas e $\beta$-globinas, variantes que também apresentam expressão do gene $\mathrm{HbS}$ capaz de causar falcização. ${ }^{2}$

Apesar dos avanços obtidos na realização do diagnóstico e na terapêutica da DF, a sobrevivência média ainda não conseguiu superar a quinta década de vida, com uma expectativa de vida global estimada em torno dos 30 anos de idade, principalmente em regiões onde o diagnóstico precoce, o acesso à profilaxia com uso de penicilina e imunização pneumocócica, bem como o tratamento com Hidroxiureia são mais difíceis. ${ }^{1}$

A mortalidade por DF ainda é uma realidade mundial assombrosa, principalmente nos países do continente africano, onde a alta prevalência da doença e as altas taxas mortalidade são alarmantes. Entre as regiões brasileiras, a menor taxa de mortalidade por 100.000 habitantes foi observada nas regiões Sul e Norte de 0,05 e 0,19, respectivamente. Já a maior foi encontrada na região Centro-Oeste, com 0,35, com destaque para a maior concentração no estado de Goiás, que expressa uma taxa de 0,48 mortes por 100.000 habitantes. O valor é semelhante ao encontrado no estado da Bahia, que possui a maior taxa de mortalidade da região nordeste, também com 0,48 óbitos por 100.000 habitantes. $^{3}$

Além disso, o quantitativo de estudos sobre o tema no Brasil ainda é limitado. Até o ano de 2017, oito artigos haviam sido publicados sobre mortalidade de pessoas com DF, sem aumento expressivo de publicações no ano seguinte. ${ }^{4}$ Os mencionados artigos abordaram características e causas de mortalidade em apenas cinco dos 26 estados brasileiros. Em mais de $50 \%$ dessas pesquisas as populações estudadas foram específicas, como por exemplo, em crianças, gestantes e usuários de hidroxiureia. Somente um abordou os fatores de risco para morte em gestantes com DF.

Dessa forma, ao considerar as taxas de mortalidade mundial e nacional, a baixa expectativa de vida dos indivíduos com DF e as lacunas existentes em relação aos aspectos que envolvem sua mortalidade, faz-se necessário investigar os estudos realizados mundialmente sobre a temática mortalidade e seus fatores de risco, a fim de produzir indicadores que possam colaborar com o aumento da sobrevida dessa população.

Nesse contexto, este estudo propõe produzir uma referência robusta no sentido de compilar os estudos existentes e que abordam de modo pontual e regionalizado os dados sobre mortalidade por DF e apresentar uma análise global sobre a temática. A partir da identificação dos fatores de risco que aumentam as chances de morte, se pretende identificar aqueles capazes de receberem intervenções por parte da equipe multiprofissional, em especial, à enfermagem, como forma de diminuir a mortalidade precoce dos pacientes com DF e aumentar a sobrevida com garantia de uma melhor qualidade de vida a esses indivíduos.

Assim, objetivou-se neste estudo sumarizar os fatores de risco e os indicadores de mortalidade em pacientes com doença falciforme.

\section{MÉTODO}

Trata-se de um estudo de revisão integrativa da literatura que consiste em um método rigoroso, que utiliza critérios pré-definidos acerca da questão norteadora, extração, análise e discussão dos dados. ${ }^{5}$ Além disso, permite a combinação de diversos métodos e possibilita ao pesquisador analisar e sintetizar o conhecimento científico a respeito do objeto do estudo, de modo a identificar lacunas existentes. ${ }^{6}$

Para a operacionalização desta pesquisa, foram realizadas as seguintes etapas: elaboração da questão norteadora, estabelecimento de critérios de inclusão e exclusão, busca ou amostragem na literatura, coleta de dados, categorização dos estudos, análise crítica dos estudos incluídos, discussão dos resultados e apresentação da revisão integrativa. ${ }^{7}$

A questão norteadora foi elaborada por meio do uso da estratégia PVO, onde $\mathrm{P}$ (population) corresponde à população de pacientes com doença falciforme, o V (variable) se refere à variável de interesse que diz respeito aos fatores de risco e indicadores de mortalidade, por último o $\mathrm{O}$ (outcome) consiste no resultado, aqui considerado a mortalidade. ${ }^{8}$ Assim, construiu-se a seguinte questão norteadora: Quais os fatores de risco e os indicadores relacionados com a mortalidade de pacientes com doença falciforme?

A busca nas bases de dados ocorreu nos meses de outubro e novembro de 2018 e foi realizada por dois pesquisadores independentes, de modo a evitar o viés de seleção. Utilizou-se o Proxy licenciado pela Universidade Federal do Rio Grande do Norte por meio da Coordenação de Aperfeiçoamento de Pessoal de Nível Superior (CAPES) (http://www.capes.gov.br/), o qual foi acessado via Portal de Periódicos CAPES (http://www-periodicoscapes-gov-br.ez18.periodicos.capes.gov.br/), nos mesmos dias e horários.

Os dados foram coletados nas seguintes bases de dados: CINAHL, PubMed, Science Direct, SciELO, Scopus e Web of Science. As discordâncias foram resolvidas por consenso, com comparação dos resultados das buscas e verificação das diferenças dos achados.

Para busca nas bases de dados foram utilizados os seguintes descritores indexados e suas respectivas sinonímias do Medical SubjectHeadings (MeSH):\#1 Anemia, Sickle Cell (HbS Disease OR Hemoglobin S Disease OR Sickle Cell Anemia OR Sickle Cell Disease OR Sickle Cell Disorders OR Sickling Disorder 
Due to Hemoglobin S) AND \#2 Mortality (age-specific death rate $O R$ case fatality rate $O R$ death rate $O R$ decline, mortality $O R$ determinants, mortality $O R$ differential mortality $O R$ excess mortality OR mortality decline OR mortality determinants $O R$ mortality rate $O R$ mortality, differential OR mortality, excess) AND \#3 Survival.

Esta pesquisa tem como objeto principal de estudo a mortalidade dos pacientes com DF. Entretanto, utilizou-se na estratégia de busca nas bases de dados o descritor "sobrevida" de modo a aumentar o número de artigos que abordaram o tema, uma vez que ao se estudar a sobrevida é possível identificar os dados de mortalidade de uma determinada população.

Os cruzamentos dos termos MeSH nas bases de dados foram combinados entre si por meio do conector booleano "AND", já os entry terms foram combinados pelo conector booleano "OR". O cruzamento adotado em todas as bases foi \#1 AND \#2 AND \#3.

Foram incluídos artigos completos, disponíveis nas bases de dados adotadas, que abordassem os fatores de risco e as respectivas taxas de mortalidade em DF, em qualquer idioma e sem recorte temporal, a fim de explorar ao máximo as publicações acerca da temática e que contemplassem o delineamento de seguimento prospectivo, estudos de intervenção ou revisão sistemática com metanálise, uma vez que estes produzem indicadores de mortalidade com maior acurácia, pois são estudos que possibilitam produzir medidas de incidência e, consequentemente, medidas diretas de risco. ${ }^{9}$

Para análise e extração dos dados foi elaborado um instrumento especificamente para os fins deste estudo com as seguintes informações: tipo de estudo, país, idioma, área de conhecimento, instituição sede de estudo, delineamento, revista ou jornal científico de publicação, população, amostragem e objetivo do estudo, além das variáveis a serem investigadas.

O processo de busca e seleção dos artigos da amostra final encontra-se descrito na Figura 1. Os resultados estão apresentados de forma descritiva e em quadro.

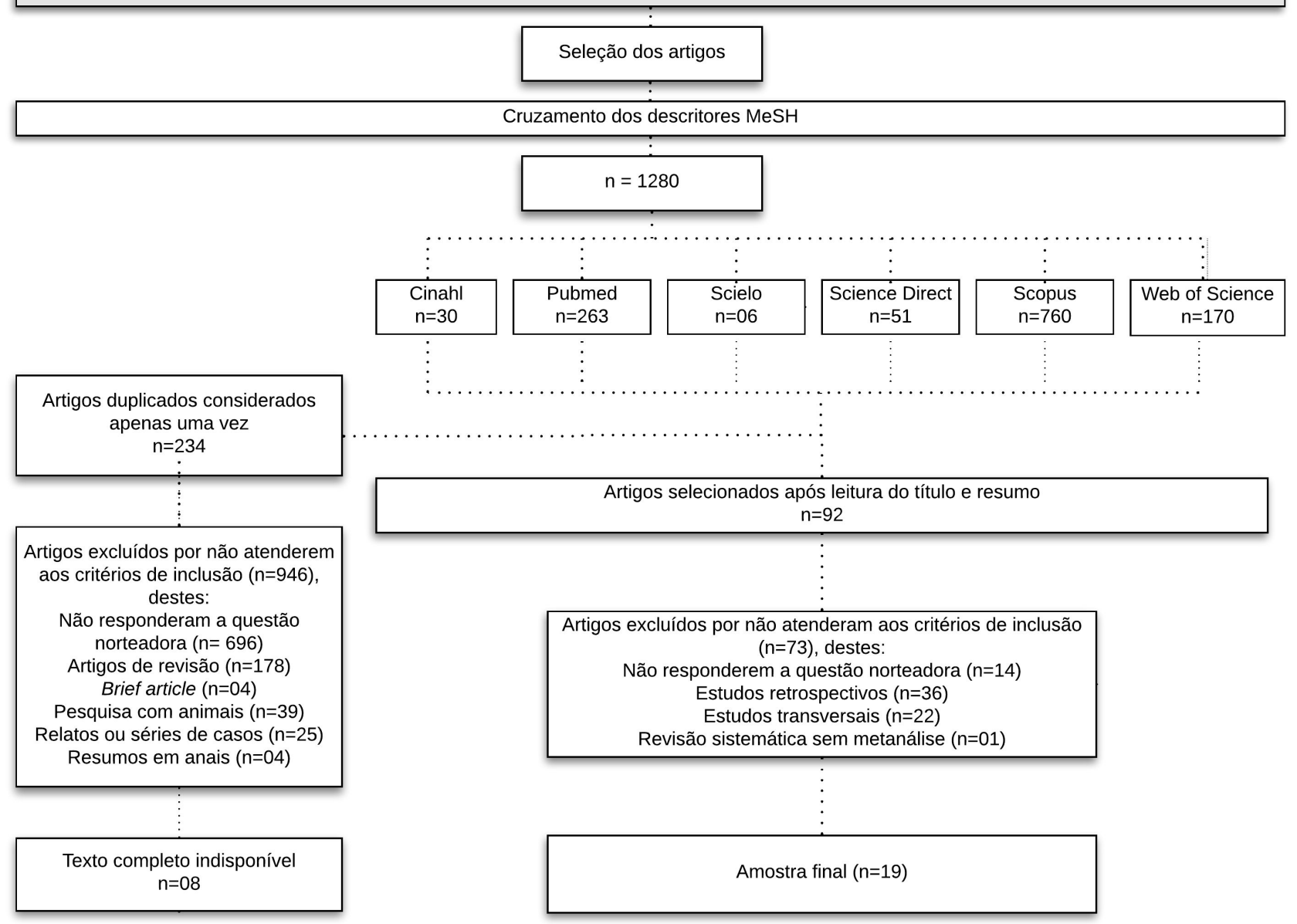

Figura 1. Fluxograma de busca para composição da amostra do estudo de revisão integrativa. Fonte: Dados da pesquisa. Campo Grande/MS, Brasil, 2019. 


\section{RESULTADOS}

A busca nas bases de dados totalizou, inicialmente, 1.280 artigos. Após a aplicação dos critérios de inclusão e exclusão, foram selecionados 19 artigos ${ }^{10-28}$ para composição da amostra final, todos publicados em língua inglesa.

Desta amostra, 10 artigos estavam indexados nas bases de dados Web of Science/Scopus, ${ }^{10,12,14,15,17-19,21,23,27}$ três na PubMed/Scopus/Web of Science, ${ }^{16,26,28}$ dois na Scopus ${ }^{20,22}$ e os demais publicados uma única vez nas bases PubMed, ${ }^{24}$ Web of Science, ${ }^{25}$ PubMed/Scopus ${ }^{13}$ e CINAHL/Scopus/Web of Science, ${ }^{11}$ respectivamente.

Em relação à distribuição geográfica e temporal, observou-se que oito estudos $(42,1 \%)$ foram realizados nos Estados Unidos da América (EUA), ${ }^{12,13,15-17,24,26,28}$ três na Jamaica, ${ }^{14,20,25}$ dois no Reino Unido ${ }^{20,27}$ e Tanzânia ${ }^{19,21}$ e um na Nigéria, ${ }^{22}$ França, ${ }^{23}$ Holanda ${ }^{18}$ e Canadá/Estados Unidos. ${ }^{11}$ Os anos com maior número de publicações foram $2013^{12,20,27}$ e $2011^{18,19,21}$ com três publicações cada e os anos $2005,{ }^{17,22} 2010^{15,28}$ e $2015^{14,16} \mathrm{com}$ duas publicações cada. A publicação mais antiga é de $2001^{25}$ e os dois estudos mais recentes foram publicados no ano de $2015 .{ }^{14,16}$

Após a análise e síntese dos artigos selecionados para esta revisão, com o objetivo de facilitar a leitura e compreensão, os resultados foram agrupados em três categorias: $(A)$ Genótipos dos participantes dos estudos; (B) Indicadores de mortalidade e (C) Fatores de risco para morte, esse último dividido em fatores laboratoriais e fatores clínicos, sociodemográficos e comorbidades.

No Quadro 1, é possível visualizar a distribuição dos 19 artigos analisados na amostra final, segundo base de dados, primeiro autor, número da referência, ano de publicação, periódico, país onde foi desenvolvido, delineamento do estudo, objetivo do estudo e principais resultados.

Quadro 1. Caracterização dos estudos da amostra final da revisão integrativa.

\begin{tabular}{|c|c|c|c|c|}
\hline Base & $\begin{array}{l}\text { Primeiro autor, } \\
\text { número da } \\
\text { referência, ano, } \\
\text { periódico, país }\end{array}$ & Delineamento & Objetivos & Principais resultados \\
\hline $\begin{array}{l}\text { Scopus, } \\
\text { Web of } \\
\text { Science }\end{array}$ & $\begin{array}{c}\text { Telfer et al. }{ }^{10} \\
\text { Haematologica } \\
\text { Journal } \\
\text { Reino Unido }\end{array}$ & $\begin{array}{c}\text { Estudo } \\
\text { de coorte } \\
\text { prospectivo }\end{array}$ & $\begin{array}{l}\text { Investigar os resultados } \\
\text { em uma coorte neonatal } \\
\text { como uma referência } \\
\text { para atendimento de } \\
\text { crianças com doença } \\
\text { falciforme. }\end{array}$ & $\begin{array}{c}\text { A taxa de mortalidade global } \\
\text { para HbSS foi de 0,13 por } \\
100 \text { pacientes/ano. A probabilidade de } \\
\text { sobrevida aos } 10 \text { e } 20 \text { anos para HbSS foi } \\
\text { de } 99 \% \text { e a taxa de mortalidade foi de } \\
\text { 0,27 por } 100 \text { pacientes/ano. }\end{array}$ \\
\hline $\begin{array}{l}\text { CINAHL, } \\
\text { Scopus, } \\
\text { Web of } \\
\text { Science }\end{array}$ & $\begin{array}{l}\text { Steinberg et al. }{ }^{11} \\
\text { JAMA Network } \\
\text { Canadá e Estados } \\
\text { Unidos da América }\end{array}$ & $\begin{array}{c}\text { Estudo } \\
\text { de coorte } \\
\text { prospectivo }\end{array}$ & $\begin{array}{c}\text { Determinar se a } \\
\text { hidroxiureia atenua } \\
\text { a mortalidade em } \\
\text { pacientes com anemia } \\
\text { falciforme. }\end{array}$ & $\begin{array}{c}\text { A mortalidade cumulativa aos } 09 \text { anos foi } \\
\text { de } 28 \% \text { para os níveis de hemoglobina } \\
\text { fetal }<0,5 \mathrm{~g} / \mathrm{dL} \text { e de } 15 \% \text { quando } \\
\text { eram } \geq 0,5 \mathrm{~g} / \mathrm{dL}(\mathrm{p}<0,03) \text {. Contagem } \\
\text { de reticulócitos }<250.000 / \mathrm{mm}^{3} \text { e } \\
\text { hemoglobina }<9 \mathrm{~g} / \mathrm{dL} \text { tiveram aumento na } \\
\text { mortalidade }(\mathrm{p}=0,002) \text {. }\end{array}$ \\
\hline $\begin{array}{l}\text { Scopus, } \\
\text { Web of } \\
\text { Science }\end{array}$ & $\begin{array}{l}\text { Mehari et al. }{ }^{12} \\
\text { American journal } \\
\text { of respiratory } \\
\text { and critical care } \\
\text { medicine } \\
\text { Estados Unidos da } \\
\text { América }\end{array}$ & $\begin{array}{c}\text { Estudo } \\
\text { de coorte } \\
\text { prospectivo }\end{array}$ & $\begin{array}{l}\text { Identificar os fatores } \\
\text { de risco associados à } \\
\text { mortalidade e estimar a } \\
\text { sobrevida esperada em } \\
\text { uma coorte de pacientes } \\
\text { com anemia falciforme } \\
\text { com hipertensão } \\
\text { pulmonar (HP). }\end{array}$ & $\begin{array}{c}\text { A mortalidade foi maior em pacientes } \\
\text { com HP quando comparados aos sem } \\
\text { HP ( } p<0,001) \text {. A taxa de mortalidade } \\
\text { cumulativa em } 05 \text { anos para pacientes com } \\
\text { HP foi de } 31,7 \% \text { enquanto pacientes sem } \\
\text { HP tiveram taxa de mortalidade de } 14,4 \% \text {. } \\
\text { A mediana de sobrevida para doença } \\
\text { falciforme com HP foi de } 6,8 \text { anos a partir } \\
\text { do diagnóstico. }\end{array}$ \\
\hline
\end{tabular}


Quadro 1. Continuação...

\begin{tabular}{|c|c|c|c|c|}
\hline Base & $\begin{array}{l}\text { Primeiro autor, } \\
\text { número da } \\
\text { referência, ano, } \\
\text { periódico, país }\end{array}$ & Delineamento & Objetivos & Principais resultados \\
\hline $\begin{array}{l}\text { Scopus, } \\
\text { Web of } \\
\text { Science }\end{array}$ & $\begin{array}{l}\text { King et al. }{ }^{14} \\
\text { The Journal of } \\
\text { pediatrics } \\
\text { Jamaica }\end{array}$ & $\begin{array}{l}\text { Estudo } \\
\text { de coorte } \\
\text { prospectivo }\end{array}$ & $\begin{array}{l}\text { Comparar a mortalidade } \\
\text { em crianças }<5 \text { anos } \\
\text { de idade com doença } \\
\text { falciforme na Jamaica. }\end{array}$ & $\begin{array}{l}\text { Ocorreram oito mortes em } \\
\text { crianças menores de cinco anos. } \\
\text { A idade média da morte foi de } \\
2,0 \pm 1,5 \text { anos. A taxa de mortalidade foi } \\
\text { de } 3,1 \text { por } 1000 \text { pessoas/ano com taxa de } \\
\text { mortalidade padronizada de } 0,52 \text {. }\end{array}$ \\
\hline $\begin{array}{l}\text { Scopus, } \\
\text { Web of } \\
\text { Science }\end{array}$ & $\begin{array}{c}\text { Quinn et al. }{ }^{15} \\
\text { Blood Journal } \\
\text { Estados Unidos da } \\
\text { América }\end{array}$ & $\begin{array}{l}\text { Estudo } \\
\text { de coorte } \\
\text { prospectivo }\end{array}$ & $\begin{array}{l}\text { Estimar a sobrevida em } \\
18 \text { anos para recém- } \\
\text { nascidos com anemia } \\
\text { falciforme e documentar } \\
\text { mudanças nas causas e } \\
\text { idades de morte ao longo } \\
\text { do tempo. }\end{array}$ & $\begin{array}{c}\text { Para os pacientes com HbSS/HbS } \beta \text { a } \\
\text { probabilidade de sobrevida estimada aos } \\
18 \text { anos foi de } 93,9 \% \text { e para HbSC/HbS } \beta+ \\
\text { foi de } 98,4 \% \text { ( } p=0,009) \text {. A probabilidade de } \\
\text { sobrevida aos cinco anos de idade foi de } \\
96,8 \%(1983-1990), 97,5 \% \text { (1991-2000) e } \\
99,2 \% \text { (2001-2007). }\end{array}$ \\
\hline $\begin{array}{l}\text { PubMed, } \\
\text { Scopus, } \\
\text { Web of } \\
\text { Science }\end{array}$ & $\begin{array}{c}\text { Van Beers et al. }{ }^{16} \\
\text { Circulation research } \\
\text { Estados Unidos da } \\
\text { América }\end{array}$ & $\begin{array}{l}\text { Estudo } \\
\text { de coorte } \\
\text { prospectivo }\end{array}$ & $\begin{array}{l}\text { Para avaliar a relação } \\
\text { entre ferro, inflamação } \\
\text { e morte precoce em } \\
\text { doença falciforme. }\end{array}$ & $\begin{array}{l}\text { As curvas de sobrevida por níveis de } \\
\text { proteína } C \text { reativa }(P C R) \text { tiveram diferença } \\
\text { estatística entre os grupos com maior } \\
\text { mortalidade para níveis } \geq 0,8 \mathrm{mg} / \mathrm{dL} \\
\text { ( } p=0,0017) \text {, além disso cada aumento na } \\
\text { PCR estava associada a taxa de risco de até } \\
3,0 \text { para morte }(p<0,0001) \text {. }\end{array}$ \\
\hline $\begin{array}{l}\text { Scopus, } \\
\text { Web of } \\
\text { Science }\end{array}$ & $\begin{array}{c}\text { Shankar et al. }{ }^{17} \\
\text { American journal of } \\
\text { haematology } \\
\text { Estados Unidos da } \\
\text { América }\end{array}$ & $\begin{array}{l}\text { Estudo } \\
\text { de coorte } \\
\text { prospectivo }\end{array}$ & $\begin{array}{l}\text { Avaliar o padrão de } \\
\text { utilização de cuidados } \\
\text { médicos e mortalidade } \\
\text { em crianças e adultos } \\
\text { com doença falciforme. }\end{array}$ & $\begin{array}{l}\text { Para menores que cinco anos com DF a taxa } \\
\text { de mortalidade não diferiu das outras crianças } \\
\text { negras da população estudada. A mortalidade } \\
\text { foi maior para idade de } 10 \text { e } 19 \text { anos. Entre } \\
20 \text { a } 49 \text { anos a mortalidade foi maior para } \\
\text { sexo masculino }(p<0,001)\end{array}$ \\
\hline $\begin{array}{l}\text { Scopus, } \\
\text { Web of } \\
\text { Science }\end{array}$ & $\begin{array}{c}\text { Van der Plas et al. }{ }^{18} \\
\text { British journal of } \\
\text { haematology } \\
\text { Holanda }\end{array}$ & $\begin{array}{l}\text { Estudo } \\
\text { de coorte } \\
\text { prospectivo }\end{array}$ & $\begin{array}{l}\text { Coletar informações sobre } \\
\text { a taxa de mortalidade e } \\
\text { as causas de morte em } \\
\text { crianças com Anemia } \\
\text { falciforme na Holanda } \\
\text { antes da triagem neonatal. }\end{array}$ & $\begin{array}{l}\text { A taxa de mortalidade global foi de } \\
0,27 \text { mortes por } 100 \text { pacientes/ano e a } \\
\text { probabilidade de sobrevida estimada } \\
\text { aos } 03 \text { e } 18 \text { anos foi de } 98,2 \% \text { e } 97,3 \% \text {, } \\
\text { respectivamente. }\end{array}$ \\
\hline $\begin{array}{l}\text { Scopus, } \\
\text { Web of } \\
\text { Science }\end{array}$ & $\begin{array}{c}\text { Makani et al. }{ }^{19} \\
\text { PloS One Journal } \\
\text { Tanzânia }\end{array}$ & $\begin{array}{l}\text { Estudo } \\
\text { de coorte } \\
\text { prospectivo }\end{array}$ & $\begin{array}{l}\text { Determinar a incidência } \\
\text { e fatores associados } \\
\text { à morte por doença } \\
\text { falciforme em } \\
\text { Dar-es-Salaam. }\end{array}$ & $\begin{array}{l}\text { A taxa de mortalidade global para a coorte foi } \\
\text { de } 1,9 \text { por } 100 \text { pessoas/ano e para menores } \\
\text { de cinco anos e em maiores de } 20 \text { anos foi } \\
\text { de } 7,3 \text { e } 1,8 \text { respectivamente. Os fatores } \\
\text { de risco independentes para morte foram } \\
\text { a hemoglobina baixa }(p<0,001) \text { e níveis } \\
\text { elevados de bilirrubina total }(p=0,020) \text {. }\end{array}$ \\
\hline Scopus & $\begin{array}{l}\text { Knight- } \\
\text { Madden et al. }{ }^{20} \\
\text { Lung Journal } \\
\text { Jamaica }\end{array}$ & $\begin{array}{l}\text { Estudo } \\
\text { de coorte } \\
\text { prospectivo }\end{array}$ & $\begin{array}{l}\text { Determinar se a asma, } \\
\text { função pulmonar } \\
\text { reduzida, episódios de } \\
\text { síndrome torácica aguda } \\
\text { e/ou tabagismo predizem } \\
\text { a mortalidade em } \\
\text { pacientes com anemia } \\
\text { falciforme. }\end{array}$ & $\begin{array}{c}\text { A taxa de mortalidade para a população de } \\
\text { estudo foi de } 1,6 \text { por } 100 \text { pacientes/ano. } \\
\text { A taxa de mortalidade entre pacientes } \\
\text { com anemia falciforme foi maior que a } \\
\text { dos controles }(p=0,03) \text {. Entre os fatores } \\
\text { de risco para morte foram observados } \\
\text { o estado de asma atual }(p=0,002) \text { e o } \\
\text { tabagismo }(p=0,006) \text {. }\end{array}$ \\
\hline
\end{tabular}


Quadro 1. Continuação...

\begin{tabular}{|c|c|c|c|c|}
\hline Base & $\begin{array}{l}\text { Primeiro autor, } \\
\text { número da } \\
\text { referência, ano, } \\
\text { periódico, país }\end{array}$ & Delineamento & Objetivos & Principais resultados \\
\hline $\begin{array}{l}\text { Scopus, } \\
\text { Web of } \\
\text { Science }\end{array}$ & $\begin{array}{l}\text { Cox et al. }{ }^{21} \\
\text { Haematologica } \\
\text { Journal } \\
\text { Tanzânia }\end{array}$ & $\begin{array}{l}\text { Estudo } \\
\text { de coorte } \\
\text { prospectivo }\end{array}$ & $\begin{array}{l}\text { Determinar se o estado } \\
\text { nutricional deficiente } \\
\text { prevê a morbidade e } \\
\text { mortalidade em uma } \\
\text { coorte de pacientes com } \\
\text { anemia falciforme. }\end{array}$ & $\begin{array}{l}\text { Níveis menores e hemoglobina foram } \\
\text { associados ao aumento da chance de } \\
\text { desnutrição em DF. A taxa de mortalidade } \\
\text { foi de } 2,5 \text { por } 100 \text { pessoas/ano e não } \\
\text { foi associada a nenhuma medida } \\
\text { antropométrica. }\end{array}$ \\
\hline Scopus & $\begin{array}{l}\text { Akinyanju et al. } .^{22} \\
\text { Clinical and } \\
\text { Laboratory } \\
\text { Haematology } \\
\text { Nigéria }\end{array}$ & $\begin{array}{c}\text { Estudo } \\
\text { de coorte } \\
\text { prospectivo }\end{array}$ & $\begin{array}{l}\text { Examinar o resultado } \\
\text { do cuidado holístico nas } \\
\text { taxas de mortalidade, } \\
\text { admissão hospitalar e } \\
\text { transfusão de sangue. }\end{array}$ & $\begin{array}{l}\text { Houve uma diminuição constante na taxa de } \\
\text { mortalidade de } 20,7 \% \text { em } 1988 \text { para } 0,6 \% \\
\text { em } 1995 \text { ( } p<0,0001) \text {. Com a implementação } \\
\text { dos cuidados holísticos houve diminuição } \\
\text { nas internações ( } p<0,0001 \text { ) e nas } \\
\text { transfusões de sangue }(p<0,00001) \text {. }\end{array}$ \\
\hline $\begin{array}{l}\text { Scopus, } \\
\text { Web of } \\
\text { Science }\end{array}$ & $\begin{array}{l}\text { Mekontso } \\
\text { Dessap et al. } .^{23} \\
\text { American Journal } \\
\text { of Respiratory } \\
\text { and Critical Care } \\
\text { Medicine } \\
\text { França } \\
\end{array}$ & $\begin{array}{l}\text { Estudo } \\
\text { de coorte } \\
\text { prospectivo }\end{array}$ & $\begin{array}{c}\text { Avaliar as mudanças nas } \\
\text { pressões pulmonares e } \\
\text { biomarcadores cardíacos } \\
\text { durante a síndrome } \\
\text { torácica aguda grave e } \\
\text { suas associações com a } \\
\text { morte. }\end{array}$ & $\begin{array}{l}\text { A mortalidade geral para pacientes com } \\
\text { hipertensão pulmonar foi de } 12,9 \% \text { e a } \\
\text { sobrevida foi significativamente menor para } \\
\text { pacientes com velocidade de regurgitação } \\
\text { do jato da válvula tricúspide } \geq 3 \mathrm{~m} / \mathrm{s} \text { quando } \\
\text { comparados a valores }<3 \mathrm{~m} / \mathrm{s} \text { durante a } \\
\text { síndrome torácica aguda }(\mathrm{p}=0,007) \text {. }\end{array}$ \\
\hline PubMed & $\begin{array}{c}\text { Meier et al. }{ }^{24} \\
\text { American Journal of } \\
\text { Hematology } \\
\text { Estados Unidos da } \\
\text { América }\end{array}$ & $\begin{array}{l}\text { Estudo } \\
\text { de coorte } \\
\text { prospectivo }\end{array}$ & $\begin{array}{l}\text { Testar a hipótese } \\
\text { que a detecção } \\
\text { precoce (infância) de } \\
\text { reticulocitose, anemia ou } \\
\text { leucocitose é preditiva de } \\
\text { eventos adversos maiores } \\
\text { na anemia falciforme. } \\
\end{array}$ & $\begin{array}{l}\text { A idade média no momento da morte } \\
\text { foi de } 3,4 \pm 3,4 \text { anos. A contagem de } \\
\text { reticulócitos foi um fator de risco } \\
\text { independente para morte ( } p=0,011) \text {. } \\
\text { Indivíduos com menores níveis de } \\
\text { hemoglobina tiveram uma maior taxa de } \\
\text { mortalidade }(24,7 \%) \text {. }\end{array}$ \\
\hline $\begin{array}{l}\text { Web of } \\
\text { Science }\end{array}$ & $\begin{array}{c}\text { Wierenga et al. }{ }^{25} \\
\text { The Lancet } \\
\text { Jamaica }\end{array}$ & $\begin{array}{l}\text { Estudo } \\
\text { de coorte } \\
\text { prospectivo }\end{array}$ & $\begin{array}{l}\text { Estudar a expectativa } \\
\text { de vida de pacientes } \\
\text { jamaicanos com doença } \\
\text { falciforme homozigótica. }\end{array}$ & $\begin{array}{l}\text { Dos } 3301 \text { pacientes, } 290 \text { morreram. } \\
\text { A sobrevida mediana calculada por meio } \\
\text { da simulação da taxa de mortalidade em } \\
\text { excesso foi de } 53 \text { anos para os homens e } \\
\text { 58,5 para as mulheres. }\end{array}$ \\
\hline $\begin{array}{l}\text { PubMed, } \\
\text { Scopus, } \\
\text { Web of } \\
\text { Science }\end{array}$ & $\begin{array}{c}\text { Quinn et al. }{ }^{26} \\
\text { Blood Journal } \\
\text { Estados Unidos da } \\
\text { América }\end{array}$ & $\begin{array}{l}\text { Estudo } \\
\text { de coorte } \\
\text { prospectivo }\end{array}$ & $\begin{array}{l}\text { Determinar os dados } \\
\text { de sobrevivência } \\
\text { contemporâneos para } \\
\text { crianças com anemia } \\
\text { falciforme. }\end{array}$ & $\begin{array}{l}\text { A taxa de mortalidade global foi de } 0,59 \\
\text { por } 100 \text { pacientes/ano. Genótipos HbSC e } \\
\text { HbS } \beta+\text { tiveram sobrevida maior do que os } \\
\text { HbSS e HbS } \beta=(p=0,02) \text {.A sobrevida livre } \\
\text { de eventos para todos os genótipos foi de } \\
100 \% \text { aos seis meses e } 88,5 \% \text { aos } 18 \text { anos. }\end{array}$ \\
\hline $\begin{array}{l}\text { Scopus, } \\
\text { Web of } \\
\text { Science }\end{array}$ & $\begin{array}{l}\text { Zimbarra } \\
\text { Cabrita et al. }{ }^{27} \\
\text { British Journal of } \\
\text { Haematology } \\
\text { Reino Unido }\end{array}$ & $\begin{array}{c}\text { Estudo } \\
\text { de coorte } \\
\text { prospectivo }\end{array}$ & $\begin{array}{l}\text { Determinar a } \\
\text { sobrevivência de uma } \\
\text { coorte de pacientes com } \\
\text { anemia falciforme com } \\
\text { base na velocidade de } \\
\text { regurgitação do jato da } \\
\text { válvula tricúspide (VRT) } \\
\text { e descrever as diferenças } \\
\text { entre aqueles com VRT } \\
\text { elevado e normal. }\end{array}$ & $\begin{array}{l}\text { Valores de VRT } \geq 2,5 \mathrm{~m} / \mathrm{s} \text { foram } \\
\text { associados com um risco quatro vezes } \\
\text { maior de morte. A taxa de sobrevida } \\
\text { acumulada aos cinco anos foi de } 95 \% \text {. } \\
\text { Idade }(p=0,03) \text {, níveis de hemoglobina } \\
\text { ( } p=0,006) \text {, hematócrito }(p=0,002 \text { ), volume } \\
\text { corpuscular médio ( } p=0,004) \text { e tempo de } \\
\text { desaceleração da válvula mitral ( } p<0,001) \\
\text { foram considerados fatores de risco } \\
\text { para morte. }\end{array}$ \\
\hline
\end{tabular}


Quadro 1. Continuação...

\begin{tabular}{|c|c|c|c|c|}
\hline Base & $\begin{array}{l}\text { Primeiro autor, } \\
\text { número da } \\
\text { referência, ano, } \\
\text { periódico, país }\end{array}$ & Delineamento & Objetivos & Principais resultados \\
\hline $\begin{array}{l}\text { PubMed, } \\
\text { Scopus, } \\
\text { Web of } \\
\text { Science }\end{array}$ & $\begin{array}{c}\text { Steinberg et al. }{ }^{28} \\
\text { American Journal of } \\
\text { Hematology } \\
\text { Estados Unidos da } \\
\text { América }\end{array}$ & $\begin{array}{c}\text { Ensaio Clínico } \\
\text { Controlado } \\
\text { Randomizado }\end{array}$ & $\begin{array}{c}\text { Examinar os riscos } \\
\text { e benefícios do } \\
\text { uso prolongado de } \\
\text { hidroxiureia. }\end{array}$ & $\begin{array}{l}\text { A taxa de mortalidade global foi de } 4,4 \text { por } \\
100 \text { pessoas/ano. } \\
\text { A mortalidade diminuiu com o aumento } \\
\text { da exposição. Entre } 10 \text { e } 15 \text { anos, foi de } \\
\text { 1,78 por } 100 \text { pessoas/ano e após } 15 \text { anos, } \\
\text { chegou a zero. }\end{array}$ \\
\hline
\end{tabular}

\section{Genótipos dos participantes dos estudos}

Da amostra final somou-se um total de 14.594 indivíduos participantes das pesquisas, com exceção dos controles, acompanhados por uma média de 8,6 anos. Deste total, 6.059 (51,7\%) eram do sexo feminino e 5.660 (48,3\%) do masculino, mesmo com predomínio do masculino em oito estudos. ${ }^{13,15,16,18,23,24,26,28}$ Em cinco, o sexo não foi informado. ${ }^{10,11,20-22}$ Todos os artigos em que o genótipo foi descrito ${ }^{10,12,14-16,18,20-28}$ traziam o HbSS como população de estudo, que totalizou 11.394 indivíduos e constituiu $91,6 \%$ do total estudado. Os demais genótipos descritos foram observados, em um menor número de publicações, em um total de 1.047 indivíduos pesquisados. Em três estudos o genótipo não foi informado. ${ }^{11,13,17}$

\section{Indicadores de Mortalidade}

O total de óbitos encontrado nos estudos foi de 1.100, que correspondeu a 7,5\% da amostra analisada. Destes, 1.057 mortes ocorreram em indivíduos com genótipo HbSS $(96,1 \%)$ e dois estudos não relataram o número absoluto de mortes. ${ }^{16,22}$

As taxas de mortalidade que mais se repetiram foram a taxa de mortalidade cumulativa, observada em nove estudos, ${ }^{11-13,16,22-24,27,28}$ e a taxa de mortalidade global, por 100 pessoas/ano, encontrada em sete s0,15,18-21,26 $_{\text {dos }} 19$ estudos.

Essas taxas foram estratificadas por contagem de reticulócitos, ${ }^{11,14}$ por nível de hemoglobina fetal $(\mathrm{HbF})$, episódios anuais de síndrome torácica aguda (STA) e de dor, ${ }^{11}$ hipertensão pulmonar, ${ }^{12}$ proteína $\mathrm{C}$ reativa $(\mathrm{PCR}),{ }^{16}$ período de cuidados holísticos, ${ }^{22}$ níveis de hemoglobina $(\mathrm{Hb}),{ }^{24}$ velocidade de regurgitação do jato da válvula tricúspide, ${ }^{27}$ anemia falciforme grave ${ }^{23}$ e doença renal terminal ${ }^{13}$ para a taxa de mortalidade cumulativa. E genótipos mais e menos graves, ${ }^{15,26}$ anemia falciforme ${ }^{21}$ e $\mathrm{DF}^{18-21}$ para a taxa de mortalidade global.

Além destas, foi encontrada a taxa de mortalidade padronizada $(\mathrm{SMR})^{14,19}$ e o cálculo do excesso de mortalidade, ${ }^{25}$ além das taxas de mortalidade específicas: por idade, ${ }^{10,14,17,19,28}$ por idade e ano, ${ }^{15}$ idade e sexo, ${ }^{17}$ idade e genótipo. ${ }^{26}$

Entre as curvas encontradas nos estudos, estavam a curva de mortalidade global, ${ }^{18}$ curva de mortalidade relacionada à doença falciforme ${ }^{26}$ e a curva de mortalidade cumulativa estratificada por hidroxiureia versus placebo, níveis de $\mathrm{HbF}$, contagem de neutrófilos, contagem de reticulócitos, síndrome torácica aguda, episódios de dor ${ }^{11}$ e níveis de PCR. ${ }^{16}$

Entre as taxas de mortalidade encontradas, no que diz respeito à taxa de mortalidade geral para todas as formas da DF, o menor valor observado entre os estudos foi de $0,15^{17}$ e o maior de $4,4^{28}$ por 100 pessoas/ano. A taxa de mortalidade específica estratificada para os genótipos mais graves $\mathrm{HbSS}$ e $\mathrm{HbS} \beta^{\circ}$ variou entre $0,52^{15}$ e $0,59^{15,26}$ e para os genótipos $\mathrm{HbSC}$ e $\mathrm{HbS} \beta+$ de $0,1^{15}$ a $0,4^{26}$ por 100 pessoas/ano.

A aplicação de cuidados holísticos para o paciente com DF levou a uma redução da taxa de mortalidade cumulativa de $20,7 \%$ para $0,6 \%$ em sete anos, ${ }^{22}$ enquanto o não tratamento com hidroxiureia implicou em uma taxa de $46,9 \%$ em um período de 17,5 anos. ${ }^{28}$

A taxa de mortalidade específica por 100 pessoas/ano encontrada para crianças de até um ano variou de $0,55^{14}$ a 4,98.22 A maior taxa de mortalidade observada entre crianças de até dois anos foi de 0,72 para o genótipo $\mathrm{HbSS}^{26}$ e para crianças de até cinco anos variou de $0,36^{17}$ a $6,77^{28} \mathrm{com}$ taxa de mortalidade cumulativa de $55,7 \%$ para um período de 17,5 anos. ${ }^{28}$ Observou-se também que a taxa de mortalidade da DF apresentou elevação com o aumento da idade a partir dos cinco anos com 0,36 para menores de cinco anos, de 3,5 para adultos de 40 a 49 anos e de 7,8 para idosos com mais de 60 anos. ${ }^{17}$

Além disso, foi encontrada uma maior mortalidade para o sexo masculino a partir dos cinco anos de idade, com maior taxa de mortalidade nas faixas etárias de 40 a 49 anos e de 50 a 59 anos com 6,3 e 6,4 por 100 pessoas/ano, respectivamente. Para as mesmas idades no sexo feminino, a taxa de mortalidade, na mesma ordem, foi de 2,5 e $4,8 .{ }^{17}$

Foi possível observar nos estudos que a maior mortalidade da DF está diretamente relacionada à presença de fatores de risco. A taxa de mortalidade cumulativa, em diferentes períodos, por nível de $\mathrm{HbF}$ apresentou o maior valor de $32 \%$ quando o nível de $\mathrm{HbF}$ era baixo quando comparado com o maior nível onde a taxa foi de $15 \% .{ }^{11} \mathrm{O}$ mesmo pode ser observado na contagem de reticulócitos $>$ que $250.000 / \mathrm{mm}^{3}$ com taxa de $38 \%{ }^{11}$ e de $4,7 \%{ }^{24}$ para a contagem $<150.000 / \mathrm{mm}^{3}$, baixo nível de PCR $(<0,2 \mathrm{mg} / \mathrm{dL})$ com $12,4 \%$ e $25,8 \%$ para níveis maiores que $0,8 \mathrm{mg} / \mathrm{dL},{ }^{16}$ hemoglobina com nível $<10 \mathrm{~g} / \mathrm{dL}$ apresentou 
taxa de $24,7 \%$ e $7,3 \%$ para níveis $>10 \mathrm{~g} / \mathrm{dL},{ }^{24}$ velocidade de regurgitação do jato da válvula tricúspide $>2,5 \mathrm{~m} / \mathrm{s}$ a taxa de mortalidade cumulativa foi de $16,7 \%$ e para valores $<2,5 \mathrm{~m} / \mathrm{s}$ a taxa observada foi de $6,9 \% .{ }^{27}$

Além disso, algumas complicações também foram associadas a uma maior taxa de mortalidade cumulativa, como a presença de episódios de STA com taxa de $32 \%$ quando comparados à ausência destes com $18 \%$, três ou mais episódios anuais de dor apresentaram taxa de $27 \%$ enquanto que para uma quantidade menor que três episódios de dor no ano a taxa de mortalidade ficou em $17 \% .{ }^{11} \mathrm{~A}$ hipertensão pulmonar implicou em uma taxa de mortalidade cumulativa de $31 \%$ e $14,4 \%$ na ausência desta. ${ }^{12} \mathrm{~A}$ anemia falciforme grave e a DF associada à doença renal terminal estão associadas a uma taxa de $12,9 \%{ }^{23}$ e $44 \%,{ }^{13}$ respectivamente.

\section{Fatores de risco para mortalidade na Doença Falciforme}

Nove $(47,3 \%)$ estudos avaliaram os fatores de risco para mortalidade, ${ }^{12,13,16,19-21,23,24,27}$ sete $(88,8 \%)$ com achados estatisticamente significativos. 12,16,19,20,23,24,27 Um total de 23 variáveis agrupadas em fatores de risco laboratoriais e clínicos, sociodemográficos e comorbidades foram identificadas neste estudo e associadas a uma maior mortalidade na DF.

Dentre os fatores laboratoriais associados ao maior risco de óbito, destacou-se a variável hematológica de baixo nível de $\mathrm{Hb}^{19,24,27}$ encontrada em três estudos, além desta foi associada ao risco de morte o maior volume corpuscular médio ${ }^{27}$ e a reticulocitose. ${ }^{24}$

Os fatores laboratoriais hepáticos encontrados foram 0 aumento da bilirrubina direta, ${ }^{12,19}$ bilirrubina total, ${ }^{19}$ fosfatase alcalina, ${ }^{12}$ transaminase glutâmico oxalética $(\mathrm{TGO})^{12}$ e ferritina. ${ }^{12}$ Também foi observado como risco aumentado de morte a elevação dos níveis de PCR. ${ }^{16}$

Dentre os fatores cardiovasculares associados a maior mortalidade foram evidenciados a presença de insuficiência cardíaca com classe funcional da New York Heart Association (NYHA) II ou III, ${ }^{12}$ a capacidade de caminhada de 6 minutos $<100$ metros $^{12}$ e os achados ecocardiográficos tais como: regurgitação contínua do jato tricúspide ${ }^{26}$ e pela velocidade de regurgitação do jato da válvula tricúspide $>2,5 \mathrm{~m} / \mathrm{s},{ }^{23,27}$ aumento da pressão da artéria pulmonar ${ }^{12} \mathrm{e}$ aumento do índice de resistência vascular pulmonar. ${ }^{12}$

Estado de asma atual, ${ }^{20}$ idade elevada, ${ }^{27}$ presença de tabagismo ${ }^{20}$ e o genótipo $\mathrm{HbSS}^{12}$ também foram associados com risco de morte aumentado.

\section{DISCUSSÃO}

A presente revisão buscou investigar de forma global os indicadores e os fatores de risco para mortalidade em DF e fornecer uma visão abrangente da literatura. Os dados encontrados foram semelhantes aos apontados em outros estudos. Embora o sexo não apresente predominância genética na DF, foi observado o predomínio do sexo feminino na população pesquisada. ${ }^{29}$ Do mesmo modo, os dados observados em relação ao genótipo também estão em consonância com a literatura mundial que aponta que o HbSS é o genótipo de maior prevalência no Brasil e no mundo, e que pode chegar a cerca de $70 \%$ do total de casos de DF diagnosticados. . $^{30,31}$

Em relação a mortalidade, os dados também foram semelhantes. A maior taxa de mortalidade global encontrada foi similar à observada em um estudo realizado no estado da Bahia com 5,4:100 pessoas/ano, ${ }^{32}$ região com um dos maiores valores de mortalidade por DF do país.

Nesse contexto, embora tenha sido observado o declínio do número de mortes com a implantação de cuidados holísticos aos pacientes e o início da terapia com hidroxiureia, a DF ainda mantém elevadas taxas de mortalidade, como taxa de mortalidade cumulativa de 50,7\% para crianças de até cinco anos encontrada na amostra analisada. Dado este, que vem de encontro ao estudo realizado no estado de Mato Grosso do Sul, onde a taxa de mortalidade cumulativa aos quatro anos de idade foi de $48 \%$ para usuários de hidroxiureia e $66 \%$ para não usuários. ${ }^{30}$ Esses achados elevam a necessidade de políticas públicas de saúde globais que priorizem o diagnóstico e início de tratamento precoce dessa enfermidade, já nos primeiros anos de vida. O programa nacional de triagem neonatal é uma importante política existente no Brasil desde 2001 e que é responsável pelo diagnóstico das hemoglobinopatias nos primeiros dias após o nascimento e garante o início do tratamento já nos primeiros meses de vida. ${ }^{33}$

Além disso, a elevação da taxa de mortalidade com o aumento da idade, que pode chegar a 7,8 por 100 pessoas/ano para idosos com mais de 60 anos, corrobora com achados deste e de outros estudos que observaram o aumento da idade como um fator de risco para morte. ${ }^{34-36}$ Esses dados devem-se ao fato de que pacientes com idade avançada sofrem mais com lesões progressivas em inúmeros órgãos que decorrem das complicações crônicas e frequentes da doença falciforme ${ }^{37}$ Como tentativa de diminuir esses dados de mortalidade, é preciso que o tratamento da doença seja voltado ao controle dessas complicações crônicas de modo a garantir uma melhor qualidade de vida e uma menor mortalidade à pessoa idosa com DF.

Em relação ao gênero, a maior taxa de mortalidade observada para o sexo masculino se assemelha aos dados obtidos em outras pesquisas, ${ }^{38,39}$ embora diversos estudos também tenham encontrado uma maior taxa de mortalidade entre as mulheres principalmente no período adulto, o que reforça a não relação entre a DF e o sexo dos indivíduos.

Outro fator importante observado foi a relação direta entre as maiores taxas de mortalidade e a presença de fatores de risco. A maior taxa de morte entre os genótipos mais graves, principalmente o HbSS, foi observada em diversos estudos mundiais e reafirma a informação de que a doença falciforme homozigótica permanece como o genótipo de maior gravidade. ${ }^{40,41}$ Essa afirmativa pode ser justificada pela fisiopatologia da DF, pois quando desoxigenada a $\mathrm{HbS}$ se polimeriza, o que altera a forma do eritrócito e diminui o seu potencial de deformabilidade, 
evento fundamental em toda fisiopatologia da DF. Assim, como a doença homozigótica tende a apresentar uma maior quantidade de HbS, os eventos clínicos e complicações são mais frequentes, muitas vezes, graves e que podem culminar em óbito. ${ }^{42}$

A HbF possui papel importante na inibição da polimerização das $\mathrm{HbS}$. Dessa forma, uma maior quantidade desta hemoglobina na circulação sanguínea pode estar associada a uma diminuição dos sintomas e das complicações da doença. Atualmente, a única medicação capaz de induzir a produção de HbF é a hidroxiureia, embora o mecanismo pelo qual essa indução ocorre não esteja claro, o benefício do seu uso já foi comprovado e o protocolo de utilização é garantido na terapêutica da doença. ${ }^{43}$

Quanto aos fatores de risco, um total de 10 variáveis laboratoriais foram identificadas. A diminuição da contagem de glóbulos vermelhos, evidenciada pela baixa porcentagem de hematócrito, além do baixo nível de $\mathrm{Hb}$ e reticulocitose ${ }^{34,44,45}$ apresentaram-se como fatores de risco para morte em diversas pesquisas, assim como um maior volume corpuscular médio. ${ }^{46}$ O aumento do número de células brancas ${ }^{44,45,47,48}$ também foram associados a um maior risco de morte.

Níveis baixos de $\mathrm{Hb}$ estão associados a complicações graves uma vez que se relacionam a uma menor capacidade de carrear oxigênio o que pode levar à desoxigenação das $\mathrm{HbS} e$ consequente oclusão de vasos. O tratamento principal centra-se na transfusão sanguínea, em especial a transfusão simples de glóbulos vermelhos. ${ }^{49}$

Da mesma forma, os reticulócitos estão associados à presença de eventos clínicos importantes e são considerados preditores de gravidade da doença. Além disso, agem como marcadores de hemólise e são eliminados de forma prematura na corrente sanguínea. Seus níveis elevados indicam processo de hemólise ativo ${ }^{50}$ e o torna um marcador laboratorial importante na prática clínica.

Outras variáveis laboratoriais como as funções hepáticas, com aumento da bilirrubina direta e total, ${ }^{51}$ fosfatase alcalina, ${ }^{35,51}$ ferritina ${ }^{35,51,52}$ e da TGO, ${ }^{35}$ juntamente com o aumento dos níveis de PCR, ${ }^{40}$ considerado um marcador inflamatório, também foram encontrados em outros estudos como associados ao maior risco de morte.

Além disso, foi possível observar que a associação de algumas variáveis laboratoriais encontradas de forma isolada neste estudo, quando em conjunto, também apareceram como um fator de risco para morte em outras pesquisas. A variável derivada da associação entre a contagem de reticulócitos, lactato desidrogenase (LDH), TGO e bilirubina é denominada componente hemolítico e este foi responsável pelo aumento na mortalidade em diversas pesquisas. ${ }^{35,53}$

A doença hepática ocorre em cerca de 10 a $40 \%$ dos pacientes com DF. A crise de falcização hepática, na maior parte das vezes, é responsável pelos quadros agudos e graves da doença hepatobiliar. Além desta, o aumento dos níveis de ferro sérico, que decorre principalmente das inúmeras transfusões de sangue, podem levar a sobrecarga hepática e às complicações decorrentes deste quadro ${ }^{54}$ e sua dosagem deve ser considerada no controle laboratorial da doença. Estas variáveis estão ainda relacionadas com a hemólise intravascular, considerada uma das principais características da anemia falciforme e que podem levar a disfunções orgânicas graves e de difícil controle. ${ }^{55}$

Entre os fatores de riscos clínicos, sociodemográficos e comorbidades, 13 variáveis foram identificadas. As variáveis cardiovasculares, velocidade de regurgitação do jato da válvula tricúspide $>2,5 \mathrm{~m} / \mathrm{s}^{34,35,45,52}$ e regurgitação contínua do jato da válvula tricúspide e a insuficiência cardíaca classe funcional da NYHA II ou III ${ }^{35}$ foram associados a um maior risco de mortalidade. Estas e outras variáveis, que também refletem a disfunção ventricular diastólica e consequente hipertensão pulmonar, foram observadas como fator de risco para morte em um estudo realizado por Gladwin e que trouxe dados de uma grande coorte prospectiva de 513 pacientes com hipertensão pulmonar realizada pelo National institutes of health. ${ }^{56} \mathrm{Um}$ maior risco de morte também foi associado ao estado de asma atual, ${ }^{57} \mathrm{O}$ aumento da idade, ${ }^{34-36}$ além do genótipo HbSS que é considerado o mais grave entre os demais.

A evolução crônica da DF com episódios frequentes de vaso oclusão e hemólise levam a lesões progressivas em órgãos alvo, em especial ao sistema cardiovascular com complicações que incluem hipertensão pulmonar, elevação da pressão da artéria pulmonar e disfunção diastólica do ventrículo esquerdo, que pode culminar em insuficiência cardíaca e até mesmo arritmias e morte súbita. ${ }^{37}$ Dessa forma, é importante a avaliação clínica e cardiológica rotineira nos pacientes com DF com manejo destas complicações crônicas feito precocemente por meio da estratificação do risco de gravidade cardiovascular e avaliação dos biomarcadores de injúria cardíaca.

Foi possível observar que os dados obtidos por esse estudo evidenciaram uma elevada taxa de mortalidade da DF, principalmente frente aos fatores de risco comuns à fisiopatologia da doença, o que mantém uma elevada taxa de letalidade em especial após a terceira década de vida. Reconhecer precocemente os fatores de risco e preditores de mortalidade possibilita um tratamento adequado e com maior brevidade. Dessa forma, torna-se imperativa a necessidade de capacitação dos profissionais de saúde para o reconhecimento precoce dos sinais que levam a piora clínica e à rápida intervenção nestas complicações.

\section{CONCLUSÃO}

Indicadores de mortalidade permanecem como ferramentas que apontam para um melhor manejo dos pacientes com DF, bem como para a prevenção dos fatores de risco e suas complicações. Assim, ao esclarecer os principais fatores relacionados à morbimortalidade de pacientes com doença falciforme é possível identificar os pontos principais a serem atentados como itens para investimento com o intuito de aumentar a sobrevida e reduzir as perdas de vidas prematuras. Entretanto, novos estudos acerca da temática se fazem necessários para o avanço do conhecimento e melhoria da qualidade e expectativa de vida dessa população. 


\section{CONTRIBUIÇÃO DOS AUTORES}

Desenho do estudo de revisão. Extração de informações, análise e interpretação dos resultado. Redação e revisão crítica do manuscrito. Aprovação da versão final do artigo. Responsabilidade por todos os aspectos do conteúdo e a integridade do artigo publicado Carolina Mariano Pompeo. Extração de informações, análise e interpretação dos resultados. Redação e revisão crítica do manuscrito. Aprovação da versão final do artigo. Responsabilidade por todos os aspectos do conteúdo e a integridade do artigo publicado Andreia Insabralde de Queiroz Cardoso. Análise e interpretação dos resultados. Redação e revisão crítica do manuscrito. Aprovação da versão final do artigo. Responsabilidade por todos os aspectos do conteúdo e a integridade do artigo publicado Mercy da Costa Souza. Interpretação dos resultados. Redação e revisão crítica do manuscrito. Aprovação da versão final do artigo. Responsabilidade por todos os aspectos do conteúdo e a integridade do artigo publicado Mayara Bontempo Ferraz, Marcos Antonio Ferreira Júnior, Maria Lúcia Ivo.

\section{EDITOR ASSOCIADO}

Rafael Celestino da Silva

\section{REFERÊNCIAS}

1. Piel FB, Steinberg MH, Rees DC. Sickle cell disease. N Engl J Med. 2017;376(16):1561-73. http://dx.doi.org/10.1056/NEJMra1510865. PMid:28423290.

2. Ware RE, de Montalembert M, Tshilolo L, Abboud MR. Sickle cell disease. Lancet. 2017;390(10091):311-23. http://dx.doi.org/10.1016/ S0140-6736(17)30193-9. PMid:28159390.

3. Ministério da Saúde (BR), Departamento de Informática do SUS [Internet]. 2016 [citado 2018 jul 19]. Disponível em: http://tabnet.datasus.gov.br/ cgi/tabcgi.exe?ibge/cnv/poptdf.def

4. Arduini GA, Rodrigues LP, Trovo de Marqui AB. Mortality by sickle cell disease in Brazil. Rev Bras Hematol Hemoter. 2017;39(1):52-6. http:// dx.doi.org/10.1016/j.bjhh.2016.09.008. PMid:28270347.

5. Hopia H, Latvala E, Liimatainen L. Reviewing the methodology of an integrative review. Scand J Caring Sci. 2016;30(4):662-9. http://dx.doi. org/10.1111/scs.12327. PMid:27074869.

6. Whittemore R, Chao A, Jang M, Minges KE, Park C. Methods for knowledge synthesis: an overview. Heart Lung. 2014;43(5):453-61. http://dx.doi.org/10.1016/j.hrtlng.2014.05.014. PMid:25012634.

7. Galvão TF, Pereira MG. Revisões sistemáticas da literatura: passos para sua elaboração. Epidemiol Serv Saude. 2014;23(1):183-4. http:// dx.doi.org/10.5123/S1679-49742014000100018.

8. Andrade da Silva G, Otta E. Revisão sistemática e meta-análise de estudos observacionais em Psicologia. Rev Costarric Psicol [Internet]. 2014; [citado 2019 jan 2];33(2):137-53. Disponível em: https://www. redalyc. org/articulo.oa? id=476747238004

9. Almeida Fo N, Barreto ML. Desenhos de pesquisa em epidemiologia. In: Almeida Fo N, Barreto ML, organizadores. Epidemiologia e saúde: fundamentos, métodos e aplicações. Rio de Janeiro: Guanabara Koogan; 2011. p. 165-74.

10. Telfer P, Coen P, Chakravorty S, Wilkey O, Evans J, Newell H et al. Clinical outcomes in children with sickle cell disease living in England: a neonatal cohort in East London. Haematologica. 2007;92(7):905-12. http://dx.doi.org/10.3324/haematol.10937. PMid:17606440.

11. Steinberg $\mathrm{MH}$, Barton $\mathrm{F}$, Castro $\mathrm{O}$, Pegelow $\mathrm{CH}$, Ballas $\mathrm{SK}$, Kutlar $A$ et al. Effect of hydroxyurea on mortality and morbidity in adult sickle cell anemia: risks and benefits up to 9 years of treatment. JAMA. 2003;289(13):1645-51. http://dx.doi.org/10.1001/jama.289.13.1645. PMid:12672732.
12. Mehari A, Alam S, Tian X, Cuttica MJ, Barnett CF, Miles G et al Hemodynamic predictors of mortality in adults with sickle cell disease. Am J Respir Crit Care Med. 2013;187(8):840-7. http://dx.doi.org/10.1164/ rccm.201207-12220C. PMid:23348978.

13. McClellan AC, Luthi JC, Lynch JR, Soucie JM, Kulkarni R, Guasch A et al. High one year mortality in adults with sickle cell disease and end-stage renal disease. Br J Haematol. 2012;159(3):360-7. http:// dx.doi.org/10.1111/bjh.12024. PMid:22967259.

14. King LG, Bortolusso-Ali S, Cunningham-Myrie CA, Reid ME. Impact of a comprehensive sickle cell center on early childhood mortality in a developing country: the Jamaican experience. J Pediatr. 2015;167(3):7025.e1. PMid:26163082.

15. Quinn CT, Rogers ZR, McCavit TL, Buchanan GR. Improved survival of children and adolescents with sickle cell disease. Blood. 2010;115(17):344752. http://dx.doi.org/10.1182/blood-2009-07-233700. PMid:20194891.

16. Van Beers EJ, Yang Y, Raghavachari N, Tian X, Allen DT, Nichols JS et al. Iron, inflammation, and early death in adults with sickle cell disease. Circ Res. 2015;116(2):298-306. http://dx.doi.org/10.1161/ CIRCRESAHA.116.304577. PMid:25378535.

17. Shankar SM, Arbogast PG, Mitchel E, Cooper WO, Wang WC, Griffin MR. Medical care utilization and mortality in sickle cell disease: a population-based study. Am J Hematol. 2005;80(4):262-70. http:// dx.doi.org/10.1002/ajh.20485. PMid:16315251.

18. Van der Plas EM, Van den Tweel XW, Geskus RB, Heijboer H, Biemond BJ, Peters $\mathrm{M}$ et al. Mortality and causes of death in children with sickle cell disease in the Netherlands, before the introduction of neonatal screening. Br J Haematol. 2011;155(1):106-10. http://dx.doi. org/10.1111/j.1365-2141.2011.08806.x. PMid:21793816.

19. Makani J, Cox SE, Soka D, Komba AN, Oruo J, Mwamtemi H et al. Mortality in sickle cell anemia in Africa: a prospective cohort study in Tanzania. PLoS One. 2011;6(2):e14699. http://dx.doi.org/10.1371/ journal.pone.0014699. PMid:21358818.

20. Knight-Madden JM, Barton-Gooden A, Weaver SR, Reid M, Greenough A. Mortality, asthma, smoking and acute chest syndrome in young adults with sickle cell disease. Lung. 2013;191(1):95-100. http://dx.doi. org/10.1007/s00408-012-9435-3. PMid:23149803.

21. Cox SE, Makani J, Fulford AJ, Komba AN, Soka D, Williams TN et al Nutritional status, hospitalization and mortality among patients with sickle cell anemia in Tanzania. Haematol. 2011;96(7):948-53. http:// dx.doi.org/10.3324/haematol.2010.028167. PMid:21459787.

22. Akinyanju O, Otaigbe A, Ibidapo M. Outcome of holistic care in Nigerian patients with sickle cell anaemia. Clin Lab Haematol. 2005;27(3):195-9. http://dx.doi.org/10.1111/j.1365-2257.2005.00683.x. PMid:15938726.

23. Mekontso Dessap A, Leon R, Habibi A, Nzouakou R, Roudot-Thoraval F, Adnot $S$ et al. Pulmonary hypertension and cor pulmonale during severe acute chest syndrome in sickle cell disease. Am J Respir Crit Care Med. 2008;177(6):646-53. http://dx.doi.org/10.1164/rccm.200710-1606OC. PMid:18174543.

24. Meier ER, Wright EC, Miller JL. Reticulocytosis and anemia are associated with an increased risk of death and stroke in the newborn cohort of the Cooperative Study of Sickle Cell Disease. Am J Hematol. 2014;89(9):904-6. http://dx.doi.org/10.1002/ajh.23777. PMid:24891147.

25. Wierenga KJ, Hambleton IR, Lewis NA, Unit SC. Survival estimates for patients with homozygous sickle-cell disease in Jamaica: a clinicbased population study. Lancet. 2001;357(9257):680-3. http://dx.doi. org/10.1016/S0140-6736(00)04132-5. PMid:11247552.

26. Quinn CT, Rogers ZR, Buchanan GR. Survival of children with sickle cell disease. Blood. 2004;103(11):4023-7. http://dx.doi.org/10.1182/ blood-2003-11-3758. PMid:14764527.

27. Zimbarra Cabrita I, Mohammed A, Layton M, Ghorashian S, Gilmore A, $\mathrm{Cho} \mathrm{G}$ et al. The association between tricuspid regurgitation velocity and 5-year survival in a North West London population of patients with sickle cell disease in the United Kingdom. Br J Haematol. 2013;162(3):400-8. http://dx.doi.org/10.1111/bjh.12391. PMid:23713628.

28. Steinberg MH, McCarthy WF, Castro O, Ballas SK, Armstrong FD, Smith $W$ et al. The risks and benefits of long-term use of hydroxyurea in sickle cell anemia: a 17.5 year follow-up. Am J Hematol. 2010;85(6):403-8. http://dx.doi.org/10.1002/ajh.21699. PMid:20513116.

29. Sant'Ana PG, Araujo AM, Pimenta CT, Bezerra ML, Borges Jr SP, Martins $\mathrm{No} V \mathrm{M}$ et al. Clinical and laboratory profile of patients with sickle cell 
anemia. Rev Bras Hematol Hemoter. 2017;39(1):40-5. http://dx.doi. org/10.1016/j.bjhh.2016.09.007. PMid:28270345.

30. Araujo OMR, Ivo ML, Ferreira Jr MA, Pontes ERJC, Bispo IMGP, Oliveira ECL. Survival and mortality among users and non-users of hydroxyurea with sickle cell disease. Rev Lat Am Enfermagem. 2015;23(1):67-73. http://dx.doi.org/10.1590/0104-1169.3385.2526. PMid:25806633.

31. Streetly A, Sisodia R, Dick M, Latinovic R, Hounsell K, Dormandy E. Evaluation of newborn sickle cell screening programme in England: 2010-2016. Arch Dis Child. 2018;103(7):648-53. PMid:29104181.

32. Ramos JT, de Amorim FS, Pedroso FKF, Nunes ACC, Rios MA. Mortalidade por doença falciforme em estado do nordeste brasileiro. Rev Enferm Cent-Oeste Min. 2015;5(2):1604-12.

33. Ministério da Saúde (BR). Triagem neonatal biológica: manual técnico [Internet]. Brasilia: Ministério da Saúde; 2016 [citado 2019 jan 2]. Disponível em: http://bvsms.saude.gov.br/bvs/publicacoes/ triagem_neonatal_biologica_manual_tecnico.pdf

34. Maitra P, Caughey M, Robinson L, Desai PC, Jones S, Nouraie M et al. Risk factors for mortality in adult patients with sickle cell disease: a meta-analysis of studies in North America and Europe. Haematol. 2017;102(4):626-36. http://dx.doi.org/10.3324/haematol.2016.153791. PMid:28104703.

35. Gladwin MT, Barst RJ, Gibbs JSR, Hildesheim M, Sachdev V, Nouraie $M$ et al. Risk factors for death in 632 patients with sickle cell disease in the United States and United Kingdom. PLoS One. 2014;9(7):e99489. http://dx.doi.org/10.1371/journal.pone.0099489. PMid:24988120.

36. Kassim AA, Payne AB, Rodeghier M, Macklin EA, Strunk RC, DeBaun MR. Forced expiratory volume in 1 second is associated with earlier death in sickle cell anemia. Blood. 2015;126(13):1544-50. http://dx.doi. org/10.1182/blood-2015-05-644435.

37. Gladwin MT. Cardiovascular complications in patients with sickle cell disease. Hematology. 2017;2017(1):423-30. http://dx.doi.org/10.1182/ asheducation-2017.1.423.

38. Lobo CLC, Nascimento EM, Jesus LJC, Freitas TG, Lugon JR, Ballas SK. Mortality in children, adolescents and adults with sickle cell anemia in Rio de Janeiro, Brazil. Hematol Transfus Cell Ther. 2018;40(1):37-42. http://dx.doi.org/10.1016/j.bjhh.2017.09.006.

39. Hamideh D, Alvarez $O$. Sickle cell disease related mortality in the United States (1999-2009). Pediatr Blood Cancer. 2013;60(9):1482-6. http:// dx.doi.org/10.1002/pbc.24557. PMid:23637037.

40. Gardner K, Douiri A, Drasar E, Allman M, Mwirigi A, Awogbade M et al. Survival in adults with sickle cell disease in a high-income setting. Blood. 2016;128(10):1436-8. http://dx.doi.org/10.1182/blood-2016-05-716910. PMid:27439910.

41. Chaturvedi S, Labib Ghafuri D, Kassim A, Rodeghier M, DeBaun MR. Elevated tricuspid regurgitant jet velocity, reduced forced expiratory volume in 1 second, and mortality in adults with sickle cell disease. Am J Hematol. 2017;92(2):125-30. http://dx.doi.org/10.1002/ajh.24598. PMid:27806442.

42. Costa FF, Conran N, Fertrin KY. Anemia falciforme. In: Zago MA, Falcão RP, Pasquini R, organizadores. Tratado de hematologia. São Paulo: Atheneu; 2013. p. 205-23.

43. Nevitt SJ, Jones AP, Howard J. Hydroxyurea (hydroxycarbamide) for sickle cell disease. Cochrane Database Syst Rev. 2017;(4). http://dx.doi. org/10.1002/14651858.CD002202.pub2.
44. Serjeant GR, Chin N, Asnani MR, Serjeant BE, Mason KP, Hambleton IR et al. Causes of death and early life determinants of survival in homozygous sickle cell disease: the Jamaican cohort study from birth PLoS One. 2018;13(3):e0192710. http://dx.doi.org/10.1371/journal. pone.0192710. PMid:29494636.

45. Elmariah H, Garrett ME, Castro LM, Jonassaint JC, Ataga KI, Eckman JR et al. Factors associated with survival in a contemporary adult sickle cell disease cohort. Am J Hematol. 2014;89(5):530-5. http://dx.doi. org/10.1002/ajh.23683. PMid:24478166.

46. Li X, Du E, Lei H, Tang Y-H, Dao M, Suresh S et al. Patient-specific blood rheology in sickle-cell anaemia. Interface Focus. 2016;6(1):20150065. http://dx.doi.org/10.1098/rsfs.2015.0065. PMid:26855752.

47. Karacaoglu PK, Asma S, Korur A, Solmaz S, Buyukkurt NT, Gereklioglu $C$ et al. East Mediterranean region sickle cell disease mortality trial: retrospective multicenter cohort analysis of 735 patients. Ann Hematol. 2016;95(6):993-1000. http://dx.doi.org/10.1007/s00277-016-2655-5. PMid:27068408.

48. Curtis SA, Danda N, Etzion Z, Cohen HW, Billett HH. Longitudinal analysis of patient specific predictors for mortality in sickle cell disease. PLoS One. 2016;11(10):e0164743. http://dx.doi.org/10.1371/journal. pone.0164743. PMid:27764159.

49. Howard J. Sickle cell disease: when and how to transfuse. ASH Education Program Book [Internet].2016;2016(1):625-31. http://dx.doi.org/10.1182/ asheducation-2016.1.625.

50. Carden MA, Fasano RM, Meier ER. Not all red cells sickle the same: contributions of the reticulocyte to disease pathology in sickle cell anemia Blood Rev. 2019;100637. http://dx.doi.org/10.1016/j.blre.2019.100637. PMid:31735458.

51. Feld JJ, Kato GJ, Koh C, Shields T, Hildesheim M, Kleiner DE et al Liver injury is associated with mortality in sickle cell disease. Aliment Pharmacol Ther.2015;42(7):912-21. http://dx.doi.org/10.1111/apt.13347. PMid:26235444.

52. Darbari DS, Wang Z, Kwak M, Hildesheim M, Nichols J, Allen D et al Severe painful vaso-occlusive crises and mortality in a contemporary adult sickle cell anemia cohort study. PLoS One. 2013;8(11):e79923. http://dx.doi.org/10.1371/journal.pone.0079923. PMid:24224021.

53. Nouraie M, Lee JS, Zhang $Y$, Kanias T, Zhao X, Xiong Z et al. The relationship between the severity of hemolysis, clinical manifestations and risk of death in 415 patients with sickle cell anemia in the US and Europe. Haematologica. 2013;98(3):464-72. http://dx.doi.org/10.3324/ haematol.2012.068965. PMid:22983573.

54. Shah R, Taborda C, Chawla S. Acute and chronic hepatobiliary manifestations of sickle cell disease: a review. World $\mathrm{J}$ Gastrointest Pathophysiol. 2017;8(3):108-16. http://dx.doi.org/10.4291/wjgp.v8.i3.108. PMid:28868180.

55. Kato GJ, Steinberg MH, Gladwin MT. Intravascular hemolysis and the pathophysiology of sickle cell disease. J Clin Invest. 2017;127(3):75060. http://dx.doi.org/10.1172/JCl89741. PMid:28248201.

56. Gladwin MT. Cardiovascular complications and risk of death in sickle-cell disease. Lancet. 2016;387(10037):2565-74. http://dx.doi.org/10.1016/ S0140-6736(16)00647-4. PMid:27353687.

57. Cohen RT, Madadi A, Blinder MA, DeBaun MR, Strunk RC, Field JJ. Recurrent, severe wheezing is associated with morbidity and mortality in adults with sickle cell disease. Am J Hematol. 2011;86(9):756-61. http://dx.doi.org/10.1002/ajh.22098. PMid:21809369. 